\title{
Transconjunctival rectus muscle bridle: an adjunct in surgical exposure
}

\author{
Harathy Selvan $\mathbb{D}^{1} \cdot$ Shikha Gupta ${ }^{1}$
}

Received: 20 October 2017 / Revised: 20 October 2017 / Accepted: 2 November 2017 / Published online: 6 February 2018

(c) The Royal College of Ophthalmologists 2018

In addition to optimised body posturing, an ideal eye position is imperative for ophthalmic surgeries for a smooth intraoperative course. In situations of long-term eso/exotropia with subsequent muscle contractures, centring the patient's eye becomes tedious. Such instances are unswerving to retro/peribulbar blocks (Fig. 1a). The usual norm resorted to in such situations is to grasp and pull the opposite limbal conjunctiva with a toothed forceps, with each surgical step, increasing the risk of conjunctival tearing and bleeding (Fig. 1b, c) due to the resistance mounted by the contracted rectus and tight conjunctiva. It also compromises the surgeon's dexterity in addition. An attempt to centre the eye with in-situ intracameral/intravitreal instruments can be tried, but may not always succeed (Fig. 1d). All these result in surgeon discomfiture, laborious manipulations, compromised glow and visibility.

To the rescue of the above, the contracted horizontal rectus muscle can be bridled with long cotton/silk sutures and clamped to the opposite territory of the sterile drape, giving a tight traction, centring the eye. After rotating the eye to the opposite gaze, the interested tendon can be grasped with superior rectus holding forceps (Fig. 2a), and bridled using Arruga's needle holder. The mean distance from the anterior limbus to the mid-point of insertions of the medial rectus and lateral rectus is $5.3 \pm 0.7$ and $6.9 \pm 0.7 \mathrm{~mm}$, respectively [1]. Hence, the respective tendons can be grasped $6 \mathrm{~mm}$ from the nasal and $7.6 \mathrm{~mm}$ from the temporal limbus. The motility of the eye corresponding to the movement of the grasped tendon confirms that the muscle has been rightly picked up. This manoeuvre not just centres the eye, but also frees the surgeon's hand and provides unrestricted room for manipulation. It maybe of undue help in lenticular and vireo-retinal surgeries, where a coaxial view is vital. In the former, by fetching maximum

Shikha Gupta, MD

dr.shikhagupta84@gmail.com

1 Dr Rajendra Prasad Centre for Ophthalmic Sciences, All India Institute of Medical Sciences, New Delhi 110029, India
Fig. 1 a Case of esotropia with extreme nasalisation even after administration of peribulbar block. b Surgeon's non-dominant hand used to grasp and pull the temporal limbal conjunctiva with Lim's forceps to aid centration. Note the tearing of conjunctiva at the site held (black arrow). Surgeon's dominant hand used to inject intracameral air bubble. $\mathbf{c}$ Difficulty in capsulorhexis due to the poor glow and limited manoeuvrability. d Inadequate centration despite appropriate intracameral instrumentation. Difficulty in accessing the nasal lens fibres highlighted

possible illumination and a worthy red glow, it aids in a confident capsulorhexis, phaco-aspiration of lens matter and assessment of the posterior capsular status [2], while in the latter it offers the view of posterior pole.

In simple cases, a peribulbar or retrobulbar block may avert this, however, in cases of long-term strabismus where the root cause is a muscle contracture, an extra mile is deemed necessary. Bridling the superior rectus is a time tested technique used for cataract and glaucoma surgeries [3, 4], which is even now resorted in difficult situations. Similarly, bridling the horizontal rectus may be adopted to centre the eyeball in cases with contractured horizontal recti (Fig. 2b).

The possible complications of this technique include bleeding, subconjunctival haemorrhage, soft tissue bridling, muscle haematoma, muscle damage and scleral perforation. However, given the familiarity and ease of this age-old technique, their chances are meagre. Also, being a one-time transconjunctival technique, the risk of overt bleeding is minimal.

In conclusion, bridling the vertical recti for cataract surgeries is well known. We extend this idea to the horizontal recti, to manage cases of long-term horizontal strabismus with tight forced duction test providing a simple solution to centre the eye and combat surgical complexity.

\section{Compliance with ethical standards}

Conflict of interest The authors declare that they have no competing interests. 

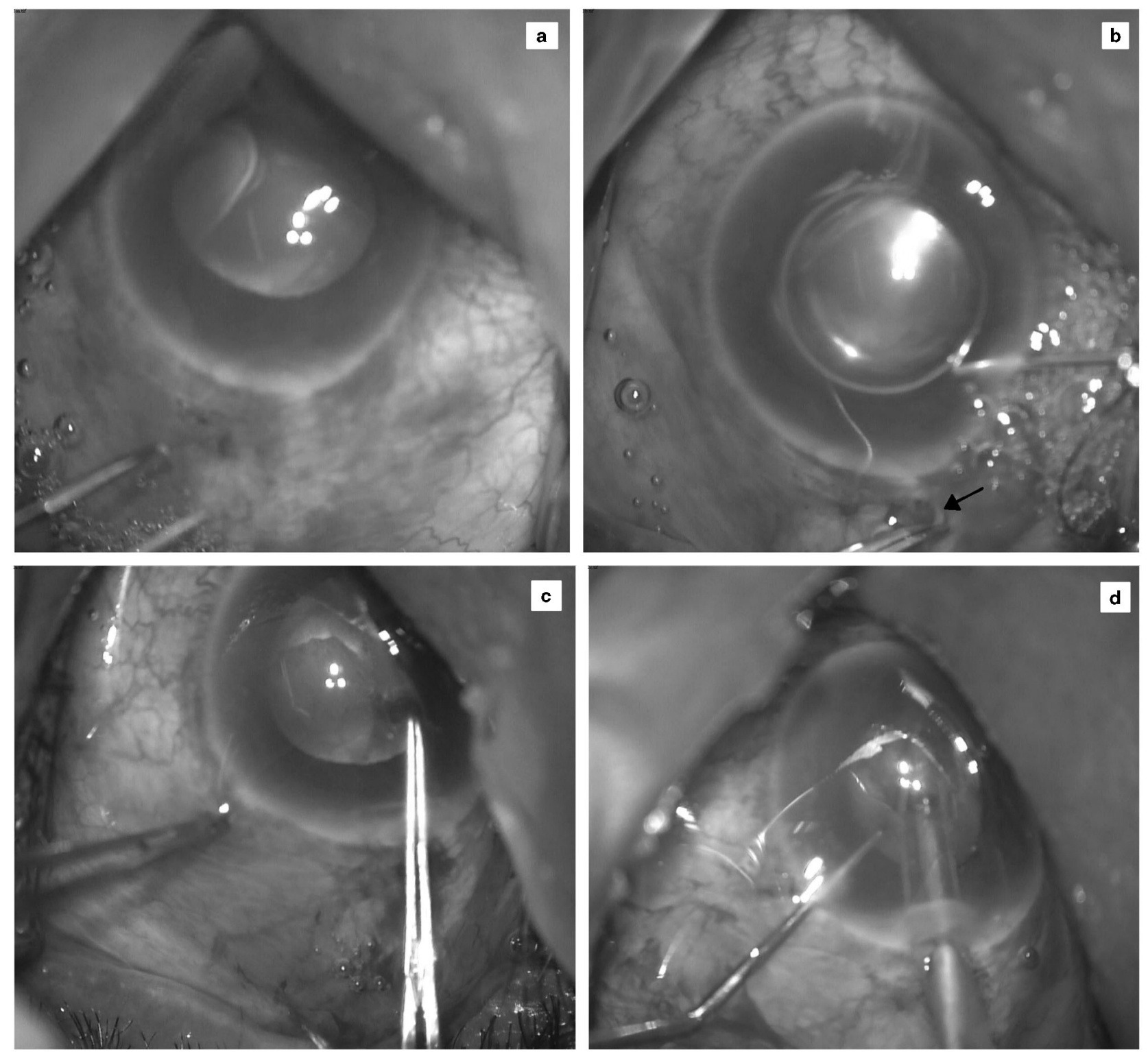

Fig. 1 For caption see previous page
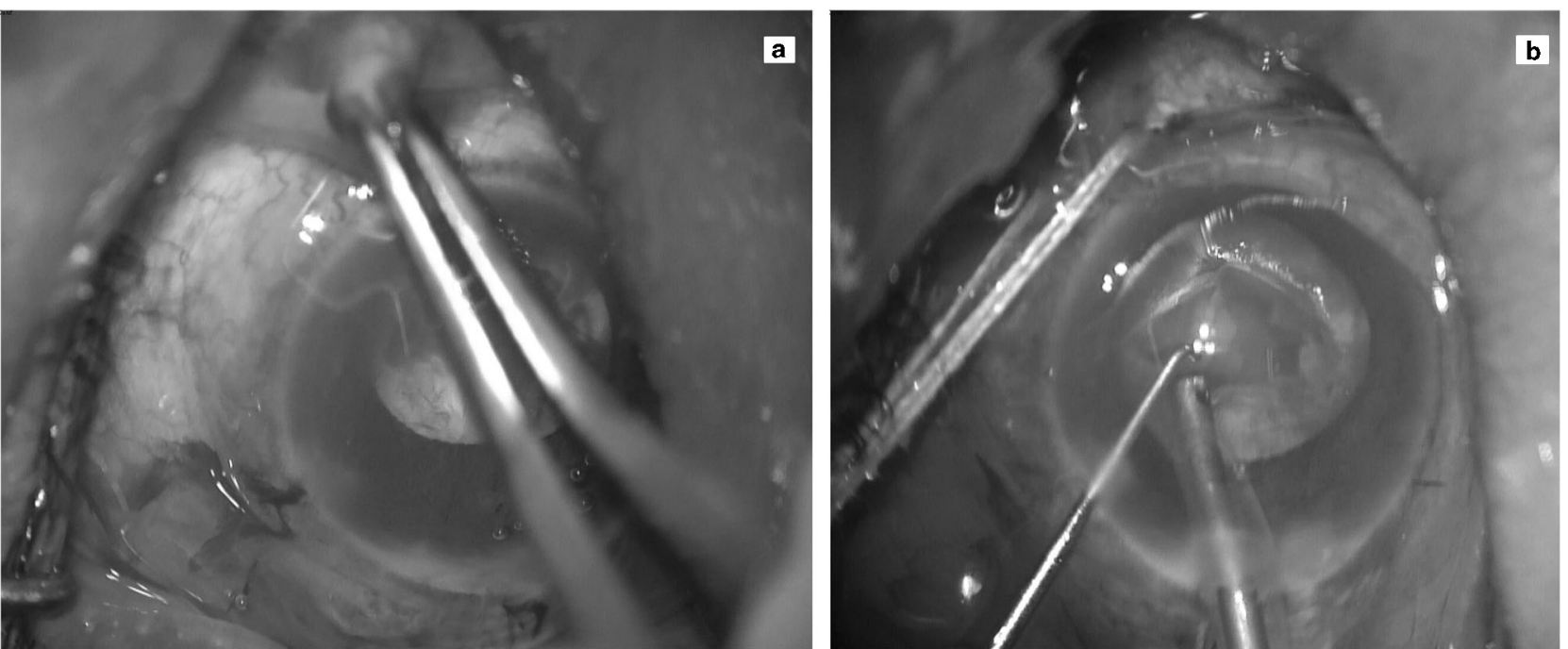

Fig. 2 For caption see next page.

SPRINGER NATURE 
Fig. 2 a Medial rectus tendon held with superior rectus holding forceps and pulled temporally to confirm lateral movement of the eyeball. b Cotton suture used to bridle the medial rectus and traction applied temporally by clamping along with the sterile drape. Note the centration of the eyeball and resultant ease to proceed the surgery

\section{References}

1. Apt L. An anatomical reevaluation of rectus muscle insertions. Trans Am Ophthalmol Soc. 1980;78:365-75.
2. Sethi HS, Dada T, Rai HK, Sethi P. Closed chamber globe stabilization and needle capsulorhexis using irrigation hand piece of bimanual irrigation and aspiration system. BMC Ophthalmol. 2005;5:21.

3. Loeffler M, Solomon LD, Renaud M. Postcataract extraction ptosis: effect of the bridle suture. J Cataract Refract Surg. 1990;16(4): $501-4$.

4. Gupta D. Glaucoma Diagnosis and Management. Lippincott Williams \& Wilkins, USA; 2005. 378 p.

\title{
Comment on: 'How to defuse a demographic time bomb: the way forward?'
}

\author{
Charles Claoué ${ }^{1}$
}

Received: 26 November 2017 / Accepted: 14 December 2017 / Published online: 9 February 2018

(c) The Royal College of Ophthalmologists 2018

I enjoyed reading the article by Buchan et al. [1], and agreed with the authors' proposals until I read that 'Bilateral cataract patients can be treated with just three hospital visits...' but surely the answer should be 2 not 3 ? If the patient has bilateral cataract and no specific contraindication, why can they not have a first hospital visit to confirm the diagnosis, obtain consent and biometry, followed by second hospital visit for ISBCS (Immediate Sequential Bilateral Cataract Surgery)? Follow-up and data on optical outcomes can be done in the community by accredited optometrists.

The risk of bilateral endophthalmitis, which has never been described with modern techniques correctly applied, is now calculated to be of the order of 1 in 12 million operations [2]. TASS should never occur and is probably rarer than endophthalmitis although hard data doesn't exist. Fears about biometry have largely been overcome with optical biometry and improved formulae such as the Hill RBF. Published data from a large American series shows no difference in outcome between ISBCS and 2 delayed sequential cataract surgery [3].

Charles Claoué

Charles@dbcg.co.uk

1 Consultant Ophthalmic Surgeon \& Company Director-DBCG Legal Ltd, Arnhem Place, London E14 3SS, UK
In seeking improvements, we should not cling to outdated fears which complicate cataract management pathways. The UK should follow other countries such as Finland where the cost advantage of $839 €$ per patient (at 2011 costs) is well recognised [4] and conversations with local ophthalmologists indicate that the majority of cataract surgery is now ISBCS.

There is nothing more powerful than an idea whose time has come.

\section{Compliance with ethical standards}

Conflict of interest The author declares that he has no competing interests.

\section{References}

1. Buchan JC, Amoaku W, Barnes B, Cassels-Brown A, Chang BY, Harcourt J, et al. How to defuse a demographic time bomb: the way forward? Eye 2017;31:1519-22.

2. Li O, Kapetanakis V, Claoué C. Simultaneous bilateral endophthalmitis after immediate sequential bilateral cataract surgery: what's the risk of functional blindness? Am J Ophthalmol. 2014;157(4):749-51.

3. Herrinton LJ, Liu L, Alexeeff S, Carolan J, Shorstein NH. Immediate sequential vs. delayed sequential bilateral cataract surgery: retrospective comparison of postoperative visual outcomes. Ophthalmology. 2017;124(8):1126-35.

4. Leivo T, Sarikkola AU, Uusitalo RJ, Hellstedt T, Ess SL, Kivelä T. Simultaneous bilateral cataract surgery: Economic analysis; Helsinki Simultaneous Bilateral Cataract Surgery Study Report 2. J Cataract Refract Surg. 2011;37:1003-8. 